\title{
Transhiatal robot-assisted esophagectomy
}

\author{
J. Boone $\cdot$ I. H. M. Borel Rinkes $\cdot$ R. van Hillegersberg
}

Received: 28 November 2007 / Accepted: 6 January 2008/Published online: 23 February 2008

(C) The Author(s) 2008

\section{Dear Editor,}

With interest we read the article by Galvani and coauthors in which they describe their initial experience with laparoscopic transhiatal esophagectomy partly aided by a robotic system [1].

Their series consists of 18 selected patients with Barrett's esophagus and high-grade dysplasia $(n=9)$, adenocarcinoma in situ $(n=2)$, superficial adenocarcinoma $(n=5)$ or T2-3 esophageal adenocarcinoma $(n=2)$ without clinical evidence of lymph node metastases. Since robot-assisted laparoscopic esophagectomy in these patients was accompanied by low blood loss, low cardiopulmonary complication rate, and no in-hospital mortality, the authors conclude their surgical technique to be a safe and effective alternative for the treatment of esophageal adenocarcinoma. We agree with the authors that this procedure may be safe and effective for the treatment of highgrade dysplasia or in situ carcinoma; however, for esophageal cancer some remarks have to be made regarding its oncological effectiveness.

The mean number of 14 lymph nodes dissected is fewer than in the open transhiatal (mean 16) and transthoracic (mean 31) approach [2]. The authors fail to describe the location of these lymph nodes, retrieved either abdominally (e.g. left gastric artery nodes) or mediastinally. Most probably the mediastinal lymphadenectomy was limited to the perioesophageal and the carinal stations. Several studies however, have shown that distal esophageal adenocarcinomas frequently metastasize to lymph nodes

J. Boone $(\bowtie) \cdot$ I. H. M. Borel Rinkes · R. van Hillegersberg Department of Surgery, University Medical Center Utrecht, Heidelberglaan 1003584 CX, Utrecht, The Netherlands e-mail: jboone2@umcutrecht.nl located in the upper mediastinum [3,4]. When performing the hybrid robot-assisted transhiatal approach, these potential metastatic lymph nodes will be left in situ. Recently, two series of robot-assisted thoracolaparoscopic esophagolymphadenectomies have been published describing a technique where a proper mediastinal lymph node dissection is performed including the bilateral paratracheal and aortopulmonary window nodes $[5,6]$.

This may be the reason for the relatively high rate of tumor recurrence in the Galvani series [1]. After a mean follow-up of 22 months, two (11\%) patients had died and three $(17 \%)$ had recurrence in a patient population with $50 \%$ of patients diagnosed with high-grade dysplasia and $50 \%$ with superficial adenocarcinoma with neither lymph node metastases nor tumor involvement in the resection margins. The technique described by Galvani et al. may therefore not be suitable for esophageal cancer, but rather for high-grade dysplasia.

Open Access This article is distributed under the terms of the Creative Commons Attribution Noncommercial License which permits any noncommercial use, distribution, and reproduction in any medium, provided the original author(s) and source are credited.

\section{References}

1. Galvani CA, Gorodner MV, Moser F, Jacobsen G, Chretien C, Espat NJ, Donahue P, Horgan S (2008) Robotically assisted laparoscopic transhiatal esophagectomy. Surg Endosc 22:188-195

2. Hulscher JB, van Sandick JW, de Boer AG, Wijnhoven BP, Tijssen JG, Fockens P, Stalmeier PF, ten Kate FJ, van Dekken H, Obertop H, Tilanus HW, van Lanschot JJ (2002) Extended transthoracic resection compared with limited transhiatal resection for adenocarcinoma of the esophagus. N Engl J Med 347:16621669

3. Feith M, Stein HJ, Siewert JR (2003) Pattern of lymphatic spread of Barrett's cancer. World J Surg 27:1052-1057 
4. Schroder W, Monig SP, Baldus SE, Gutschow C, Schneider PM, Holscher AH (2002) Frequency of nodal metastases to the upper mediastinum in Barrett's cancer. Ann Surg Oncol 9:807811

5. van Hillegersberg $\mathrm{R}$, Boone J, Draaisma WA, Broeders IA, Giezeman MJ, Borel Rinkes IHM (2006) First experience with robot-assisted thoracoscopic esophagolymphadenectomy for esophageal cancer. Surg Endosc 20:1435-1439

6. Kernstine KH, DeArmond DT, Shamoun DM, Campos JH (2007) The first series of completely robotic esophagectomies with threefield lymphadenectomy: initial experience. Surg Endosc 21:22852292 